\title{
Comparison of digital video surveys with visual aerial surveys for bird monitoring at sea
}

\author{
Ramūnas Žydelis ${ }^{1,3} \cdot$ Monika Dorsch $^{2} \cdot$ Stefan Heinänen ${ }^{1} \cdot$ Georg Nehls ${ }^{2} \cdot$ Felix Weiss $^{2}$
}

Received: 30 May 2018 / Revised: 16 December 2018 / Accepted: 19 December 2018 / Published online: 5 January 2019

(c) The Author(s) 2019

\begin{abstract}
The increasing demand for robust marine bird abundance and distribution assessments coupled with technological advances has led to the development of digital survey techniques for birds. Although digital surveys for bird monitoring are becoming a standard method in some countries, their strengths and weaknesses and comparability with traditional visual surveys remain insufficiently documented and understood. Aiming to improve existing knowledge on digital video monitoring techniques, we conducted one parallel digital video survey with 2-cm ground resolution and a 544-m swath flown at $549 \mathrm{~m}$ and an aerial visual survey flown at $76 \mathrm{~m}$ over the southern Baltic Sea in March 2015. We assessed bird sighting rates, identification rates, observed densities, and model-based abundance estimates. The digital survey covered a larger area through direct registrations, provided higher numbers of bird sightings and identified species, and higher spatial accuracy than the visual survey. Overall species identification rates were similar between the survey methods; however, there were marked differences among bird taxonomic groups: more individuals were identified to species level in the digital survey dataset for the majority of taxonomic groups, except for grebes and auks. These advantages supplement other previously identified benefits of digital aerial surveys, such as the elimination of bird disturbance due to high flight altitude, reduced observer bias, and availability of raw data for quality assurance. Furthermore, higher numbers of direct bird sightings at a higher spatial resolution during digital surveys ensure better statistical analyses, including distribution modelling, of more species for the same survey effort.
\end{abstract}

Keywords Transect sampling $\cdot$ Seabirds $\cdot$ HiDef $\cdot$ Abundance $\cdot$ Distribution

\section{Zusammenfassung}

Vergleich von digitaler Video- und visueller Flugerfassungsmethode für die Erfassung von Seevögeln

Der steigende Bedarf an belastbaren Daten zu Häufigkeit und Verbreitung von Seevögeln hat in Verbindung mit technologischen Fortschritten zur Entwicklung digitaler Erfassungsmethoden geführt. Obwohl digitale Methoden der Vogelerfassung in einigen Ländern zur Standard-Erfassungsmethode geworden sind, sind ihre Vor- und Nachteile sowie die Vergleichbarkeit mit herkömmlichen visuellen Erfassungsflügen noch unzureichend dokumentiert und verstanden. Um das vorhandene Wissen zur digitalen, videogestützen Flugerfassung zu verbessern, haben wir im März 2015 in der südlichen Ostsee einen Vergleichsflug zwischen der digitalen Video-Flugerfassung mit $2 \mathrm{~cm}$ Bodenauflösung und $544 \mathrm{~m}$ abgedeckter Streifenbreite bei einer Flughöhe von 549 m und einer parallelen visuellen Flugerfassung bei einer Flughöhe von 76 m durchgeführt. Hierfür wurden Sichtungsraten von Vögeln, Bestimmungsraten, beobachtete Dichten sowie modellbasierte Berechnungen der Abundanz untersucht. Beim digitalen Erfassungsflug wurde eine größere Fläche direkt erfasst, die digitale Methode ergab eine höhere Anzahl von Vogelbeobachtungen, eine höhere Anzahl bestimmter Arten und eine höhere räumliche Auflösung im Vergleich zur visuellen Erfassungsmethode. Die Bestimmungsrate der Vögel insgesamt betrachtet war zwischen den beiden Erfassungsmethoden ähnlich, jedoch gab es deutliche Unterschiede zwischen den taxonomischen

Communicated by F. Bairlein.

Electronic supplementary material The online version of this article (https://doi.org/10.1007/s10336-018-1622-4) contains supplementary material, which is available to authorized users.

Extended author information available on the last page of the article 
Gruppen: Für die Mehrzahl der taxonomischen Gruppen, mit Ausnahme der Lappentaucher und Alkenvögel, wurden im Datensatz des digitalen Erfassungsflugs mehr Individuen auf Artniveau bestimmt. Diese Vorteile kommen zu anderen, bereits bekannten Vorteilen der digitalen Flugerfassung hinzu, wie etwa die Vermeidung von Störungen durch die hohe Flughöhe, der reduzierte Beobachterfehler und die Verfügbarkeit von Rohdaten für die Qualitätssicherung. Darüber hinaus bietet eine höhere Anzahl von direkten Vogelbeobachtungen, die mit einer höheren räumlichen Auflösung erhoben werden, bei der digitalen Erfassungsmethode bessere Möglichkeiten für statistische Analysen, einschließlich der Möglichkeit, dass bei gleichem Erfassungsaufwand für mehr Arten räumliche Modellierungen durchgeführt werden können.

\section{Introduction}

Marine birds are notoriously difficult to survey due to their widespread and heterogeneous distributions in often difficult to access environments. The development of digital video and photo technologies opens a new field of survey methods to study numbers and distributions of seabirds and other marine animals. Recent developments in digital technologies allow high resolution on a scale of a few centimetres from high flight altitudes. It is presumed that digital survey techniques will improve the accuracy and overall quality of seabird surveys (Buckland et al. 2012). However, in order to implement a new method successfully, it is important to compare it with existing methods. Visual surveys from land, ships, and aircraft have been conducted for decades, and data from these form a comprehensive and valuable source of information on the occurrence and distribution of seabirds and marine mammals (e.g. the European Seabirds at Sea database (Reid and Camphuysen 1998)). Digital aerial surveys have already been established as a standard monitoring method for marine birds in some countries, e.g. UK and Germany [Bundesamt für Seeschifffahrt und Hydrographie (BSH) 2013]. However, up until now there have been few comparative studies, and how digital video surveys compare with traditional visual aerial surveys remains sparsely documented in the primary literature.

The earliest assessments of digital high-definition surveys focused on survey protocols and technical details of the equipment (Thaxter and Burton 2009) and compared different digital aerial survey methods with visual aerial surveys (Burt et al. 2009). The results of these early studies suggested that visual surveys provide the highest precision in bird estimates when applying correction factors from conventional distance analysis, while density surface modelling and digital survey methods at that time produced estimates with higher variability (higher coefficients of variation). Burt et al. (2009) cautioned, however, that there was insufficient coordination when the surveys were conducted, and that comparison of the survey methods was therefore inconclusive. In a study by Buckland et al. (2012), the results of digital video, digital still and visual surveys were compared when estimating the abundance of Common Scoters
(Melanitta nigra) in Carmarthen Bay, Wales. The authors concluded that estimates of two digital methods were closely comparable, while visual survey data produced substantially lower estimates. Johnston et al. (2015) reported that species identification rates at that time were lower in digital video surveys compared to ship surveys conducted in the UK; only $23 \%$ of individuals were identified to species level in digital imagery compared to $95 \%$ in ship survey records. Digital video surveys were also compared with ship surveys conducted off the mid-Atlantic coast of the US, and the results showed that more birds were observed and identified to species level from ships, except for scoters (Melanitta spp.) where identification rates were higher for digital surveys (Williams et al. 2015). However, identification rates have increased markedly with the development of improved camera technology resulting in comparable identification rates to boat-based surveys (e.g. Webb et al. 2017). Further, Red-throated Divers (Gavia stellata) were monitored using digital still and visual aerial surveys in the outer Thames estuary, UK and comparison between the two survey methods indicated similar species distribution patterns, although digital surveys recorded significantly higher densities (Skov et al. 2016).

The literature overview leads to an ambiguous conclusion about how digital aerial surveys compare with other survey techniques with regard to the monitoring of marine birds. It is likely that the performance of digital surveys is species specific, as it is for visual surveys (Diederichs et al. 2002; Camphuysen et al. 2004). Digital survey technology is likely to develop further by optimizing the technical equipment and data processing with further improvements with regard to data quality and precision. The following aspects of aerial digital surveys can be identified as being advantageous compared to visual surveys.

- Less disturbance to birds. While visual aerial surveys are usually conducted from an aircraft flying at 76-m altitude and cause sensitive species to flush (Diederichs et al. 2002), digital surveys can be conducted at heights above $460 \mathrm{~m}$, thus reducing or eliminating disturbance. Similarly, there may be positive or negative responses of birds to the surveying platform during ship surveys. 
- Higher safety. Flying aircraft at a higher altitude during digital surveys enhances the safety of such operations, especially within the boundaries of, or near, wind farms and close to bridges and oil rigs.

- Reduction of observer bias. In contrast to visual surveys, digital images are available for the time needed for the individual specialists to process and interpret the data. There is also no need for distance bias corrections of the digital data.

- Higher accuracy in object localisation. For digital data, the position of an object can be georeferenced at higher precision.

- Quality assurance of the data. Digital surveys allow all processes from object detection to identification to be quality assured, and data are stored and are available for reinspection at any time after the survey.

The challenges for digital surveys, compared to visual surveys, are primarily related to bird detection and species identification. It is important to understand the effects of environmental conditions (e.g. light, sea state), survey altitude, camera settings, and bird behaviour on detection and identification rates. We can be certain that digital aerial surveys, similar to visual aerial surveys, miss diving birds that are submerged at the time of flyover, an issue known as availability bias (Marsh and Sinclair 1989).

We conducted parallel digital video and visual aerial surveys in the southern Baltic Sea on 19 March 2015 in an area with seasonally high diversity and abundance of marine birds. The surveys were conducted during the period of peak bird abundance in the area.

The objective of the study was to compare the results of digital video and visual aerial surveys considering:

- bird sighting rates (total number of individuals registered),

- identification rates (ability to identify species),

- capacity for distribution modelling and model-based abundance estimates.

The aim of these objectives was to improve existing knowledge about the advantages and possible disadvantages of digital video techniques for monitoring marine birds at sea.

\section{Methods}

\section{Survey area}

The study was conducted in the Fehmarn Belt area, which is located in the southern Baltic Sea between Denmark and Germany. The marine and coastal areas of the Fehmarn Belt offer a wide range of habitats for breeding and non-breeding birds. The area is relatively shallow, only central parts being deeper than $20 \mathrm{~m}$. The environment is dynamic and diverse, ranging from calm bays and lagoons to offshore habitats with fast-flowing currents. The Fehmarn Belt shows intensive ship traffic with a major commercial shipping lane running longitudinally and with frequent ferry traffic traversing the site. There are also two offshore wind farms within the study area, Nysted and Rødsand 2.

\section{Survey design}

The aerial surveys were conducted using two different standard methods for recording birds at sea: a digital aerial survey recording birds using a high-definition aerial video technique (known as the 'HiDef method'); and a visual aerial survey, where birds were recorded by experienced observers during the flight using a line transect method (Camphuysen et al. 2004). Both, digital and visual surveys were flown along the same transects: the study area was covered by 23 survey transects varying from 24.8 to $54.9 \mathrm{~km}$ in length and separated by $5 \mathrm{~km}$. The digital survey plane flew first and the visual survey followed the same track with a lag time of 20-80 min. The total length of the transects flown was $651.7 \mathrm{~km}$ and the total marine area sampled by the survey transects was $3439 \mathrm{~km}^{2}$, calculated by adding a $3-\mathrm{km}$ buffer to the transects. For the purpose of this comparative study, we restricted data analyses to the areas that were covered by both digital and visual methods. Twin-engine high-wing survey planes, a Partenavia P-68 Observer and a BrittenNorman Islander BN-2, flown by professional pilots, were used for the HiDef and visual surveys, respectively.

\section{HiDef digital survey}

The digital recording during the survey was made using a rig comprising four HiDef cameras with sensors set to a ground resolution of $2 \mathrm{~cm}$ per pixel. Each camera sampled a strip of $129 \mathrm{~m}$ (cameras 2 and 3) or $143 \mathrm{~m}$ (cameras 1 and 4), separated from the next camera by approximately $20 \mathrm{~m}$ (Fig. 1). The full strip width from each camera was analysed and provided a combined sample width of $544 \mathrm{~m}$ within a 604-m overall strip, resulting in a coverage of $10.9 \%$ of the study area. The survey was flown at an altitude of $549 \mathrm{~m}$ above sea level.

The position (1-m precision) of the aircraft was captured by a Garmin GPSMap Global Positioning System (GPS) receiver 296 with differential GPS. Locations were recorded in intervals of $1 \mathrm{~s}$, which were later interpolated and used for georeferencing image frames of the video footage. Interpolated positions of the aircraft in combination with the sideways offset of the recorded images were used to georeference bird observations. All observations from an individual frame 


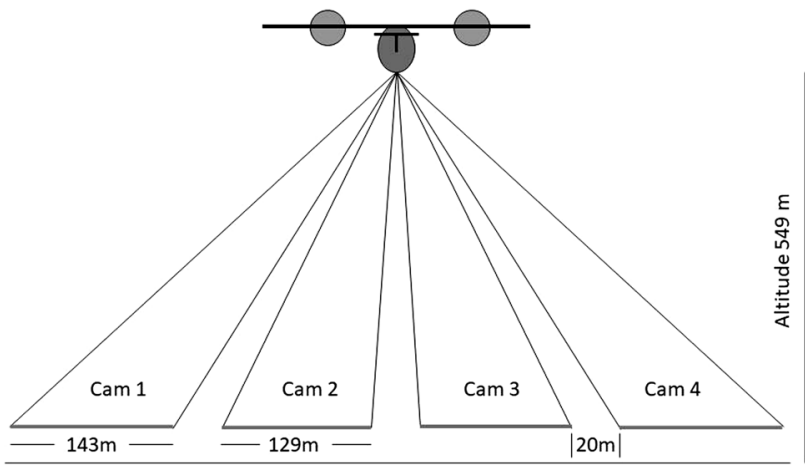

Fig. 1 Schematic illustration of transect coverage by the high-definition digital aerial survey method. A system of four cameras (Cam) covers a total strip width of $544 \mathrm{~m}$. Footage of each of the four different cameras is separated by approximately 20 -m-wide strips

were assigned the same location in the centre of the frame (marked on the frame where the observation is closest to the centre line, which results in a frame size of $143 \mathrm{~m} \times 9 \mathrm{~m}$ for cameras 1 and 4 and a frame size of $129 \mathrm{~m} \times 9 \mathrm{~m}$ for cameras 2 and 3 ).

The video footage was first reviewed by trained specialists, who marked all objects that required further identification (particularly birds and marine mammals). For quality assurance (QA) an independent audit of $20 \%$ of the raw data selected randomly was carried out and the results were compared with those of the original review. Such auditing was done separately for each camera strip. QA was only achieved if at least $90 \%$ agreement was attained, otherwise data were re-reviewed. Sections of the transect that were flown over land were excluded from the valid effort as were sections with adverse survey conditions that hindered object detection, such as low clouds between the aircraft and the water surface. The latter did not result in the exclusion of complete transects or transect sections, and only short sections recorded by single cameras were labelled as invalid effort.

In the next stage, images marked as requiring further inspection were processed by experienced ornithologists, who identified objects to the lowest possible taxonomic level. As with object detection, an independent review of $20 \%$ of all objects was carried out at random for QA. If greater than $90 \%$ agreement was not attained, a corrective action was initiated: if appropriate, the material which did not pass the identification threshold was discarded and the data re-analysed. Disputed identifications were passed to a third ornithologist for a final decision.

All objects were assigned a taxonomic species group and, where possible, each object was identified to species level. The species identifications were given a confidence rating of possible, probable or definite. Direction of flight, age, plumage, and sex were noted where possible. All confidence levels of species identifications were used in the analysis. Since detection probability of objects within the covered strip is assumed to be equal, no correction accounting for a distance detection bias is needed for digital surveys. Data were collected under good survey conditions with Douglas sea state between 1 and 2 Beaufort and good visibility $(10 \mathrm{~km})$.

\section{Visual aerial survey}

The aerial visual survey was conducted using a standard line transect technique (Buckland et al. 2001; Diederichs et al. 2002; Camphuysen et al. 2004; BSH 2007). The survey was carried out from an altitude of $76 \mathrm{~m}$. Two principal observers were each seated at bubble windows providing direct visibility below either side of the plane. Observers wore ear plugs and headphones and therefore were acoustically isolated from each other. From the onset of the survey, the observers searched continuously for birds and marine mammals. For each sighting, the exact time was noted (Coordinated Universal Time, synchronised with an onboard GPS) and recorded by speaking into a dictaphone. Survey transects were subdivided into perpendicular bands to allow calculation of distance detection probabilities. Four standard bands were used: 0-44 m, 45-167 m, 168-442 m, and $443-1500 \mathrm{~m}$. Sighted birds were identified to the lowest possible taxonomic level; group size, composition, and behaviour were also noted. The flight track was logged and stored continuously in 3-s intervals by two GPS units. Bird observations were geographically positioned by associating them with transect segments with an average length of $158 \mathrm{~m}$. Weather conditions were recorded at the start of each transect or whenever conditions changed. Survey conditions were favourable: a Douglas sea state of Beaufort 1-2 and visibility of $10 \mathrm{~km}$. The experienced observers who counted birds during visual surveys and the specialists who identified birds from video material were different individuals.

\section{Data processing and analyses}

\section{Processing of digital survey data}

All valid bird observations identified in the digital survey videos were spatially and temporarily combined with the flight effort. The observations were summed at the species or species group level per segment. The total width of all valid cameras per segment was multiplied by the measured length of each segment resulting in the area surveyed per segment. This was used to calculate the density of birds. The survey data were associated with spatially and temporally matching environmental variables using standard geographic information system and custom-built data-extraction tools (Table 1). All data were then aggregated into a $750 \times 750-\mathrm{m}$ grid by averaging densities of bird species and values of environmental variables. 
Table 1 Environmental variables considered in the distribution modelling presented separately for benthic and pelagic feeding species

\begin{tabular}{lll}
\hline Environmental variables & Benthic species & $\begin{array}{l}\text { Pelagic } \\
\text { species }\end{array}$ \\
\hline Depth & $\times$ & $\times$ \\
Proportion of hard substrate & $\times$ & $\times$ \\
Bottom slope & $\times$ & $\times$ \\
Distance to land & $\times$ & $\times$ \\
Distance to wind farms & $\times$ & $\times$ \\
Number of ships (automatic identi- & $\times$ & $\times$ \\
$\quad$ fication system) & & $\times$ \\
Pycnocline depth & & $\times$ \\
Current gradient & & $\times$ \\
Salinity & $\times$ (Bottom) & $\times$ \\
Water temperature & $\times$ (Bottom) & $\times$ \\
Current W & & $\times$ \\
Vorticity & & $\times$ \\
Current speed & $\times$ (Bottom) & \\
\hline
\end{tabular}

\section{Processing of visual survey data}

For visual surveys, the detection probability of birds declines with perpendicular distance from the transect line, usually in a non-linear manner (Buckland et al. 2001). To account for distance detection bias, distance analysis was applied using the Distance package (Miller 2015) in software R (R Core Team 2014). The objective of the distance analysis was to estimate the species-specific effective strip width (ESW), which was used to correct the observed bird number for distance detection bias (Online Resource 1).

The distance-corrected abundance in the visual aerial survey data was combined with valid survey effort, and species density per survey segment was calculated. The data were further processed in the same way as the digital data, i.e. associated with spatially and temporally matching environmental variables (Table 1) and aggregated into the $750 \times 750-\mathrm{m}$ grid. Therefore, the spatial resolution when modelling was the same for both visual and digital survey datasets.

\section{Distribution modelling}

Distribution modelling was used to predict species density distribution surfaces and produce model-based abundance estimates following the method described in Heinänen et al. (2017). Generalized additive mixed models were fitted using the mgcv R package (Wood 2011) for each species where the number of observations was sufficient for modelling per dataset (digital and visual surveys). Due to zero inflation a two-step (hurdle) model was fitted including a binomial model part and a positive gamma model part. To account for potential spatial or temporal autocorrelation, a correlation structure (corARMA) grouped by transect identifier (ID) was included. If the model did not converge with a correlation structure, it was simplified to include a random term (transect ID) instead, or changed to a simple generalised additive model. All variables were included as smooth terms in an initial full model. Non-influential (statistically insignificant) variables were excluded in a stepwise manner. The permitted $d f$ were restricted to a maximum of $5(k=5)$ or were reduced to $3(k=3)$ if the response curves showed possible model overfitting. The interaction term between $x$ and $y$ coordinates was not restricted in terms of $d f$. The predictions from both model parts were combined to yield the final density surface (Heinänen et al. 2017). Potential residual autocorrelation was assessed using a correlogram. The models were also evaluated for predictive accuracy by fitting the model to $70 \%$ of the data (randomly selected) and predicting for $30 \%$ withheld data (if sample sizes were high enough). The presence-absence model part was evaluated using the area under the receiver operator curve (Pearce and Ferrier 2000) and the overall density predictions obtained by combining both model parts were evaluated using Spearman's correlation coefficient (Heinänen et al. 2017).

\section{Results}

\section{QA of digital survey data}

Following the QA procedure of processing digital video survey data, the $90 \%$ threshold of minimum agreement between object detections by both the primary screener and independent reviewer was met for all cameras during the survey: average agreement in object detection was $97.62 \%$ (minimum-maximum: 91.51-99.71\% for different camera strips) and average agreement in object identification was $95.42 \%$ (minimum-maximum: 93.20-96.76\%). Thus no reanalysis of data was necessary for object detection or identification.

\section{Identification rates}

In total 34 marine bird species were identified in the video footage of the digital survey and 19 species were identified during the aerial visual survey (Table S1). Overall, species identification rates were high in both digital and visual surveys, i.e. $97.5 \%$ and $90.6 \%$, respectively (Table 2). However, some differences were pronounced when considering taxonomic groups separately. The digital survey identified a notably higher percentage of divers, gulls, and auks, but had a lower identification rate for grebes. However, sample sizes of grebe, geese, swan, and auk sightings were low in the visual survey data. 
Table 2 Numbers of individuals recorded and identification rates for separate taxonomic groups during the simultaneously conducted visual aerial and digital video surveys on 19 March 2015

\begin{tabular}{|c|c|c|c|c|}
\hline \multirow[t]{2}{*}{ Taxonomic group } & \multicolumn{2}{|c|}{ Visual aerial survey } & \multicolumn{2}{|c|}{ Digital video survey } \\
\hline & $\begin{array}{l}\text { Total number of } \\
\text { individuals }\end{array}$ & $\begin{array}{l}\text { Identified individu- } \\
\text { als }(\%)\end{array}$ & $\begin{array}{l}\text { Total number of } \\
\text { individuals }\end{array}$ & $\begin{array}{l}\text { Identified } \\
\text { individuals } \\
(\%)\end{array}$ \\
\hline Divers & 65 & 29.2 & 153 & 93.5 \\
\hline Grebes & 30 & 96.7 & 339 & 68.4 \\
\hline Ducks & 11,290 & 99.9 & 26,742 & 99.3 \\
\hline Geese & 172 & 100 & 213 & 91.9 \\
\hline Swans & 8 & 100 & 55 & 98.2 \\
\hline Gulls & 1979 & 38.6 & 1932 & 83.9 \\
\hline Cormorants & 148 & 100 & 225 & 100 \\
\hline Auks & 15 & 0 & 194 & 42.3 \\
\hline Total & 13,707 & 90.6 & 29,764 & 97.5 \\
\hline
\end{tabular}

\section{Observed abundance, mean densities, and total estimates}

\section{Common Eider}

The digital survey yielded a nearly 2.5 times higher number of Common Eider (Somateria mollissima) sightings compared to the visual survey, i.e. 8213 individuals registered during the visual survey and 20,160 individuals during the digital video survey (Table S1). The birds were recorded in shallow waters throughout the survey area and had similar distribution patterns (Fig. 2).

Distribution models were fitted separately for both survey methods and predicted distribution patterns matched the observed patterns closely (Figs. 2, 3). However, some mismatch between the predictions was noticed: the model based on visual survey data predicted higher densities along the Danish coast and for Rødsand Lagoon (northeastern part of the study area) where relatively few birds were registered (Fig. 2), and densities around Fehmarn Island were higher for predictions based on digital survey data (Fig. 3).

After correcting for distance detection bias, the visual survey produced a $28 \%$ lower average density of Common Eiders compared to digital survey results. The modelbased abundance estimate, however, was $25 \%$ higher for the visual survey compared to the digital survey (Table 3 ). We consider that the model-based abundance estimate of the visual survey represents over-estimated values, as it is clear from the observed and modelled distribution patterns that the visual model predicted higher peak densities and high numbers of birds in the areas where few eiders were recorded by both visual and digital surveys (e.g. Rødsand Lagoon).
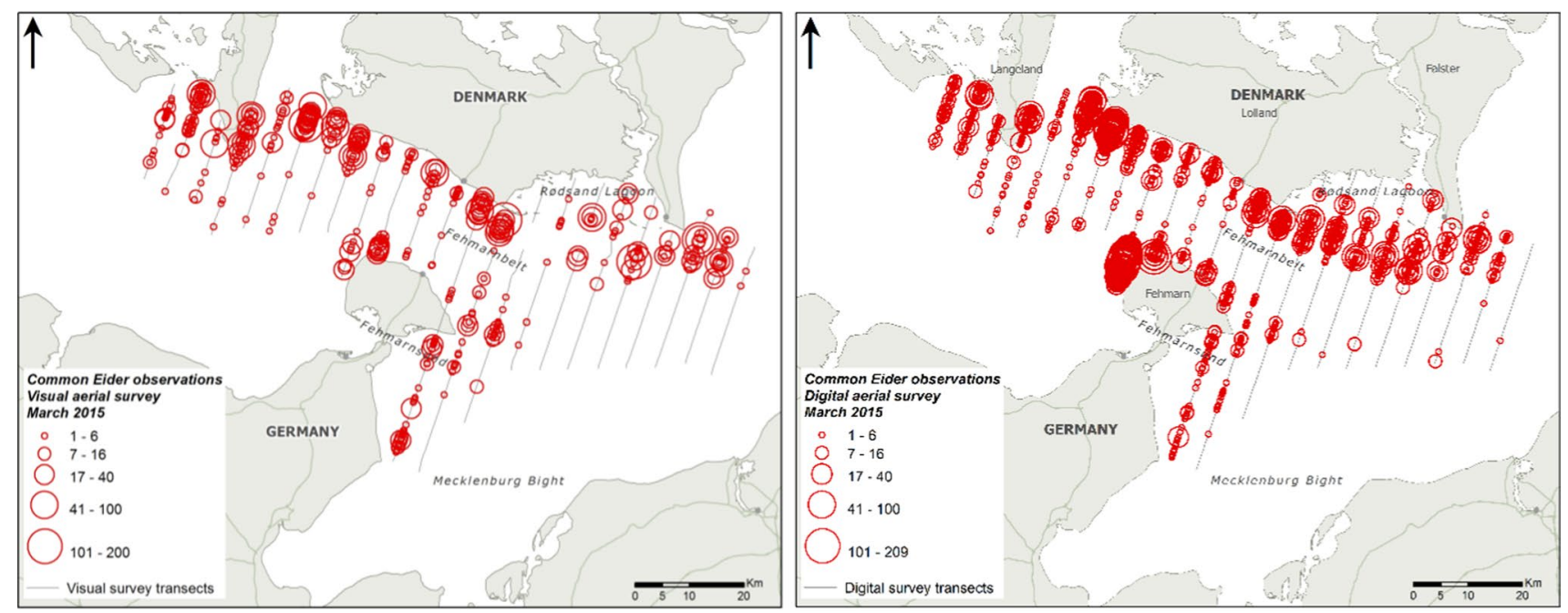

Fig. 2 Observed Common Eider distribution during visual and digital aerial surveys conducted on 19 March 2015 

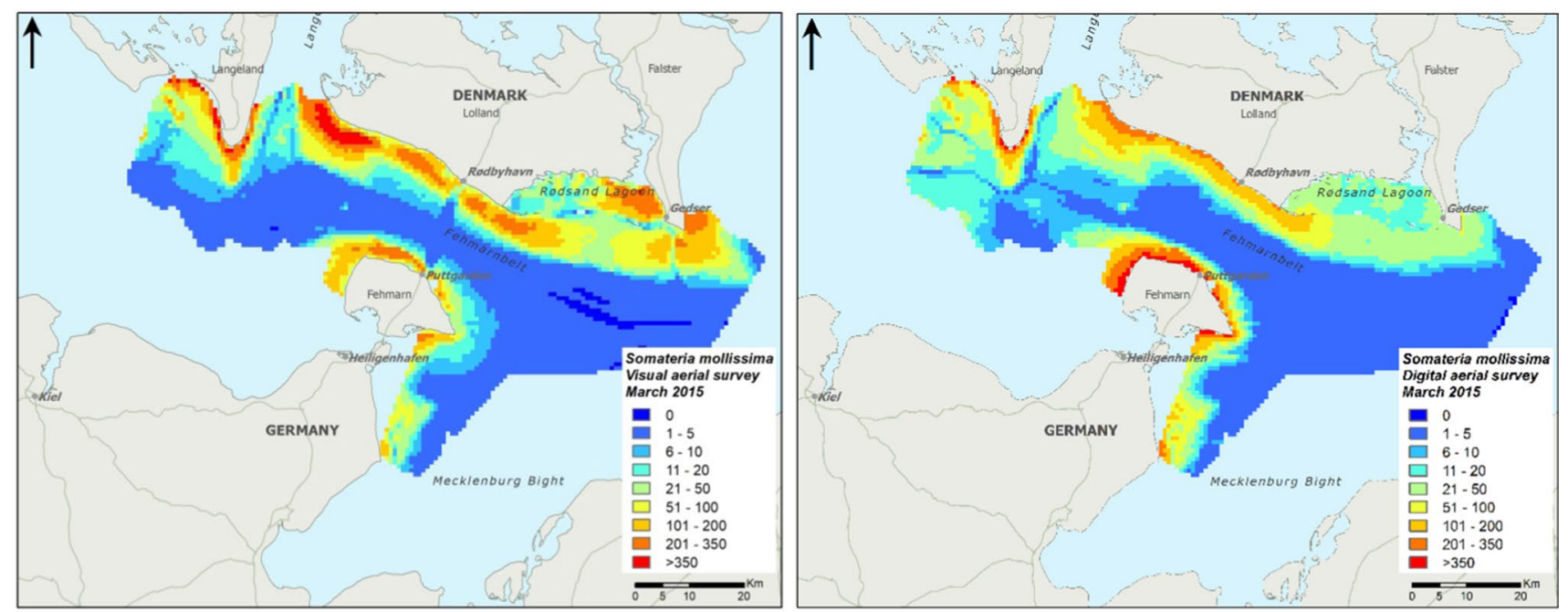

Fig. 3 Predicted Common Eider density distribution based on visual and digital aerial surveys conducted on 19 March 2015

Table 3 Model-based abundance estimates of selected species or species groups using data collected during parallel visual aerial and digital video surveys on 19 March 2015

\begin{tabular}{lcllll}
\hline Species & \multicolumn{2}{l}{ Visual aerial survey } & & \multicolumn{2}{l}{ Digital aerial survey } \\
\cline { 2 - 3 } & $\begin{array}{l}\text { Mean density } \\
\left(n / \mathrm{km}^{2}\right)\end{array}$ & $\begin{array}{l}\text { Model-based abun- } \\
\text { dance, } n( \pm \mathrm{SE})\end{array}$ & & $\begin{array}{l}\text { Mean density } \\
\left(n / \mathrm{km}^{2}\right)\end{array}$ & $\begin{array}{l}\text { Model-based abun- } \\
\text { dance, } n( \pm \mathrm{SE})\end{array}$ \\
\hline Common Eider & 42.65 & $147,307( \pm 48,031)$ & & 59.02 & $110,882( \pm 42,234)$ \\
Long-tailed Duck & 0.76 & $2474( \pm 1498)$ & & 2.04 & $7465( \pm 2773)$ \\
Common Scoter & 14.97 & $44,113( \pm 7808)$ & & 11.79 & $38,723( \pm 18,864)$ \\
Divers Gavia spp. & 0.40 & - & & 0.47 & $1648( \pm 824)$ \\
Grebes & 0.16 & - & & 1.02 & - \\
Red-breasted Merganser & 0.10 & - & & 2.95 & - \\
Auks & 0.09 & - & & 0.43 & - \\
Herring Gull & 2.89 & - & & 2.97 & - \\
\hline
\end{tabular}

\section{Long-tailed Duck}

The digital survey yielded about three times more detections of Long-tailed Ducks (Clangula hyemalis) compared to the visual survey: 259 individuals were registered by the visual survey and 797 birds during the digital video survey (Table S1).

During the visual survey, most Long-tailed Ducks were observed in the north-eastern part of the study area, whereas during the digital survey large aggregations were also registered in the southern part of the study area, as well as smaller groups of birds elsewhere in shallow waters (Fig. 4). The resulting distribution predictions and abundance estimates are therefore also different, matching the observed patterns and digital survey model that yielded a higher total abundance estimate (Fig. 5; Table 3).

The average density of Long-tailed Ducks was nearly three times lower for the visual survey (after correcting for distance detection bias) than for the digital survey (Table 3). Similarly, model-based total abundance estimate was about three times lower using the visual survey data compared to the model based on digital survey data (Table 3).

\section{Common Scoter}

In total, 2707 Common Scoters were registered during the visual survey and 4205 birds during the digital video survey (Table S1). Both aerial survey methods depicted the same high density areas of this species (Fig. 6). The modelled distribution patterns for both survey methods were generally similar; however, they had marked differences in densities and peak aggregations, which were higher based on visual survey data (Fig. 7).

After correcting for distance detection bias, average Common Scoter densities were about $20 \%$ higher for visual surveys (Table 3). Modelled total abundance estimates were also similar between the two methods, although the visual dataset gave a value that was about $12 \%$ greater (Table 3 ). 

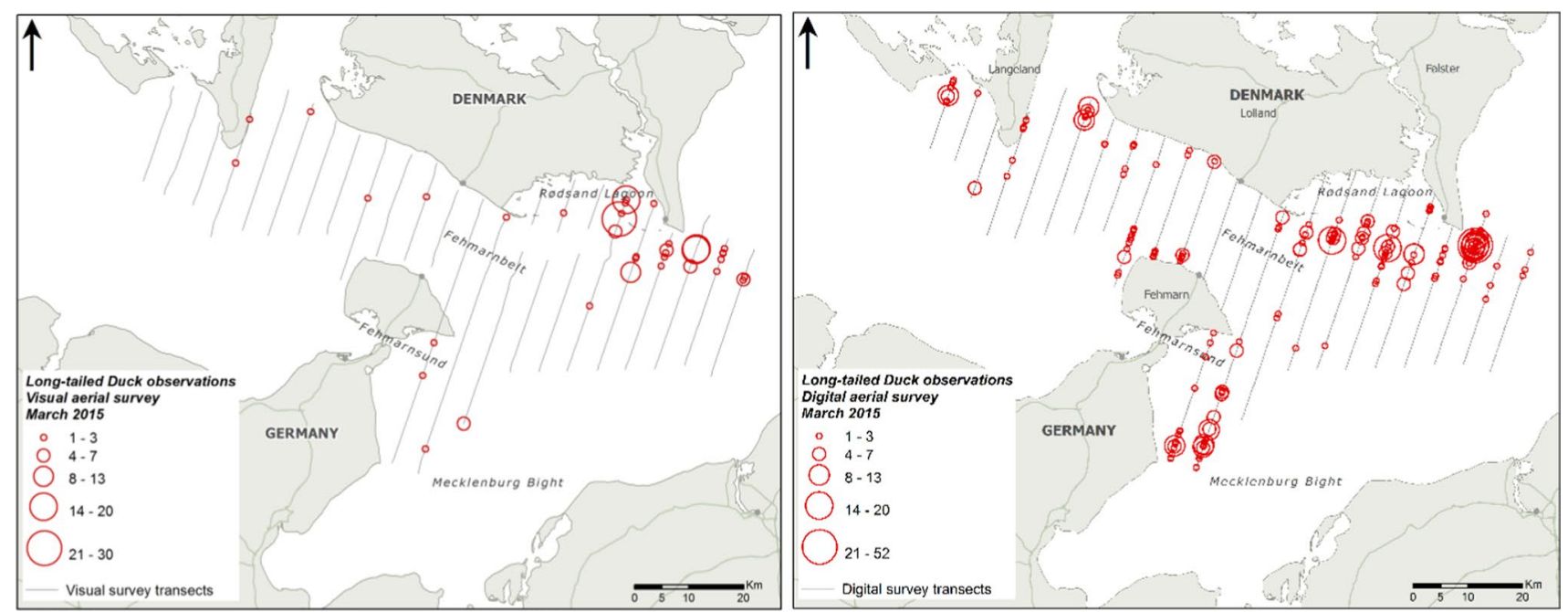

Fig. 4 Observed Long-tailed Duck distribution during visual and digital aerial surveys conducted on 19 March 2015
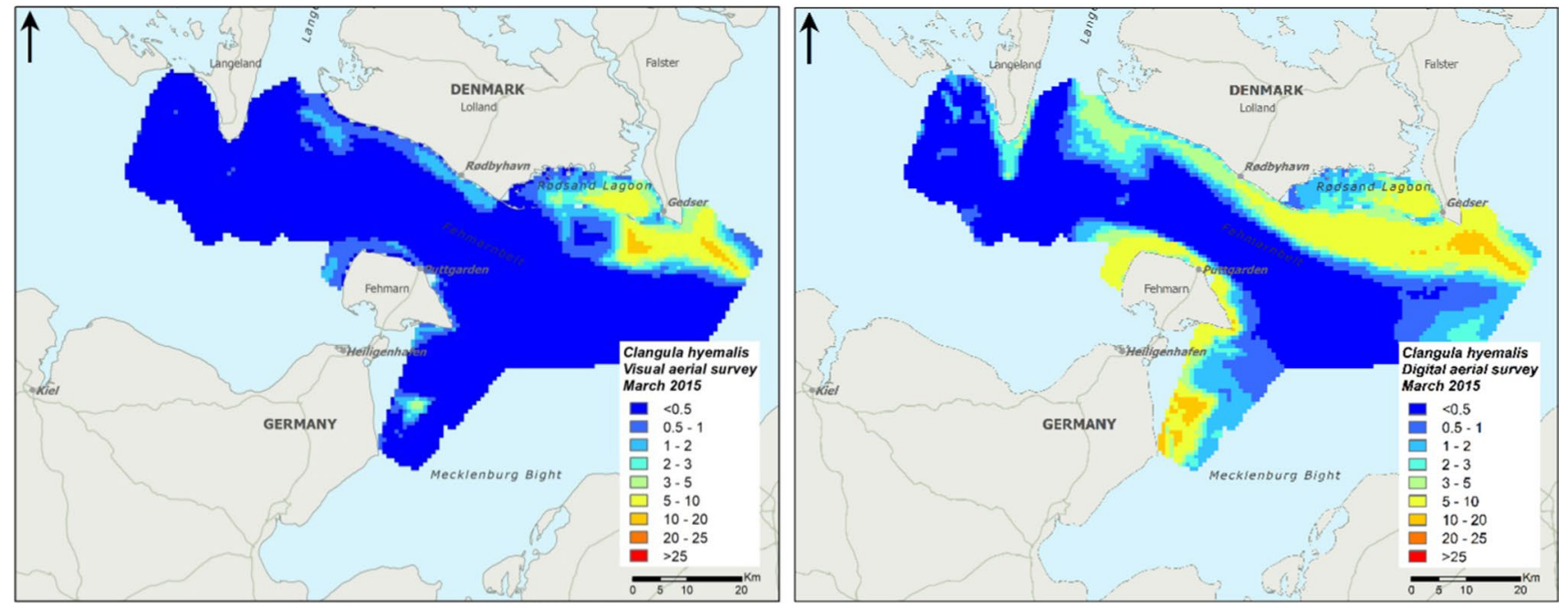

Fig. 5 Predicted Long-tailed Duck density distribution based on visual and digital aerial surveys conducted on 19 March 2015

\section{Divers}

The Red-throated Diver (Gavia stellata) is the most common species of divers in the study area; the Black-throated Diver (Gavia arctica) is less numerous here. In our analyses both species were treated together, as diver identification rate to species level was low in the visual survey dataset.

In total, 65 divers were registered during the visual survey and 153 during the digital video survey (Table S1). Both survey methods agreed reasonably well in detecting higher numbers of divers north and east of Fehmarn. However, there were sightings where these birds were detected by one method but not by the other (Fig. 8).

Distribution modelling was only possible for the digital dataset (Fig. 9), as the visual survey produced too few observations ( $n=39$ in the aggregated dataset) to fit a reliable distribution model. Even after applying the correction for distance detection bias, the visual survey produced about a $15 \%$ lower average density of divers compared to the digital survey (Table 3 ).

\section{Grebes}

Three grebe species were registered, the most common of which was the Great Crested Grebe (Podiceps cristatus) followed by the Slavonian Grebe (Podiceps auritus), and Red-necked Grebe (Podiceps grisegena). Identification of the Red-necked Grebe in non-breeding plumage from digital survey data is uncertain, and it is likely that a number of 

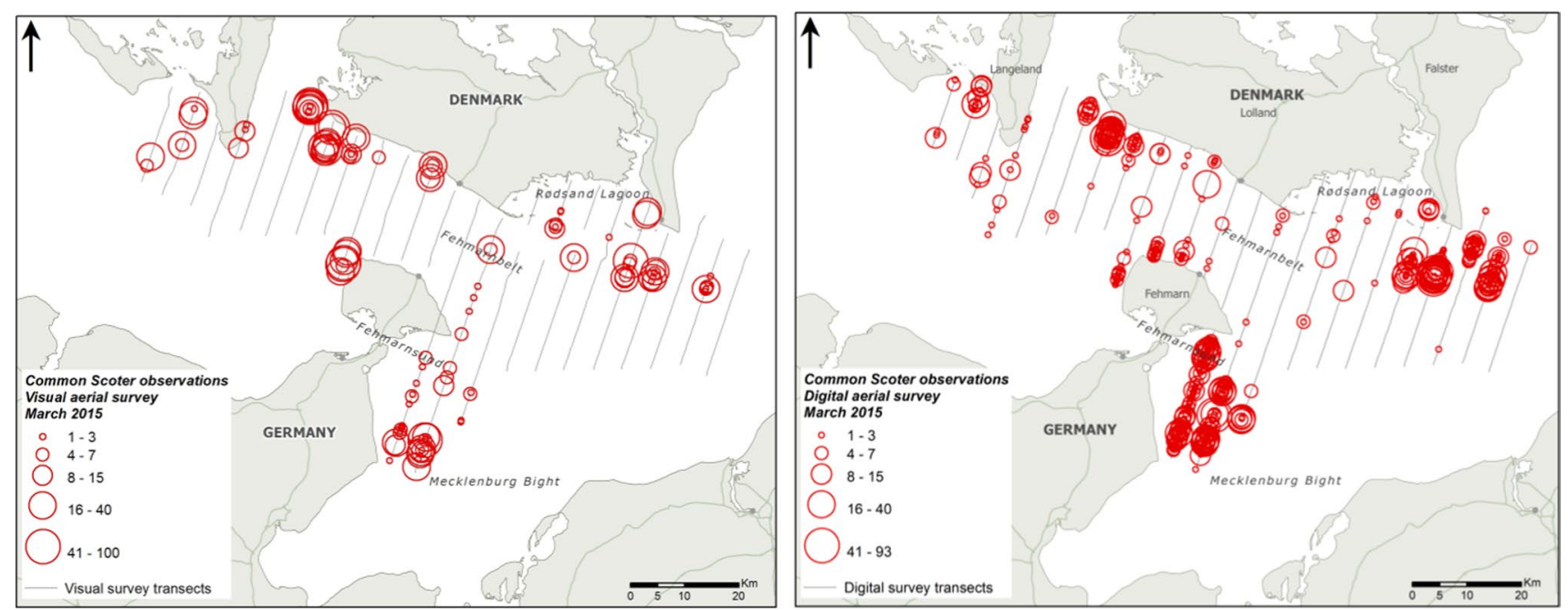

Fig. 6 Observed Common Scoter distribution during visual and digital aerial surveys conducted on 19 March 2015
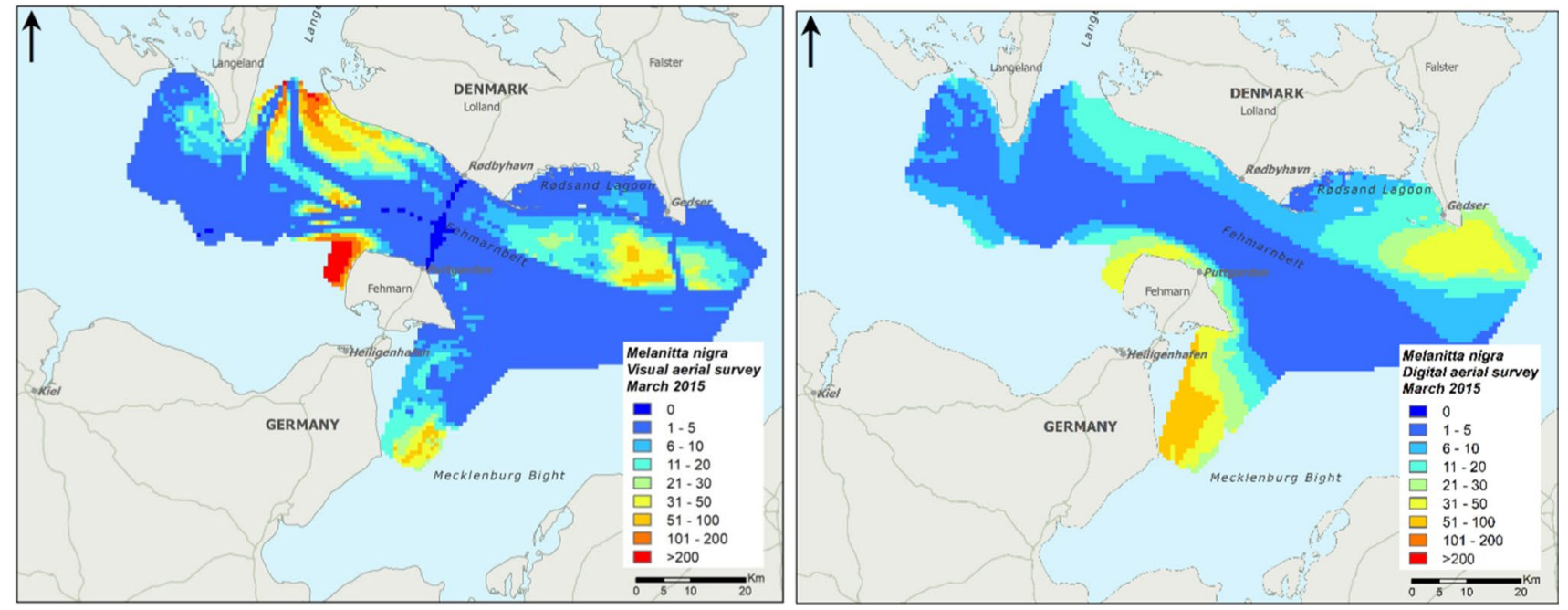

Fig. 7 Predicted Common Scoter density distribution based on visual and digital aerial surveys conducted on 19 March 2015

the unidentified grebes belong to this species. Therefore all grebe species are reported as pooled data.

During the visual survey, 30 grebe individuals were recorded, whereas 339 grebes were registered during the simultaneously conducted digital video survey (Table S1). After correcting grebe numbers in the visual survey dataset for distance detection bias, the average density was still more than six times lower than the analogous value estimated using the digital survey dataset (Table 3).

\section{Red-breasted Merganser}

The Red-breasted Merganser (Mergus serrator) was the most abundant merganser species registered during the March surveys. During the visual survey, 23 individuals were recorded, whereas 912 birds were registered during the digital video survey. After correcting Red-breasted Merganser numbers for distance detection bias in the visual survey dataset, the average density was nearly 30 times lower than the analogous value estimated using the digital video survey data (Table 3).

\section{Auks}

Razorbill (Alca torda) and Common Guillemot (Uria aalge) are the two common auk species occurring in the study area. Because auks are often not identified to species level, especially in visual surveys, we treated these two species together. 

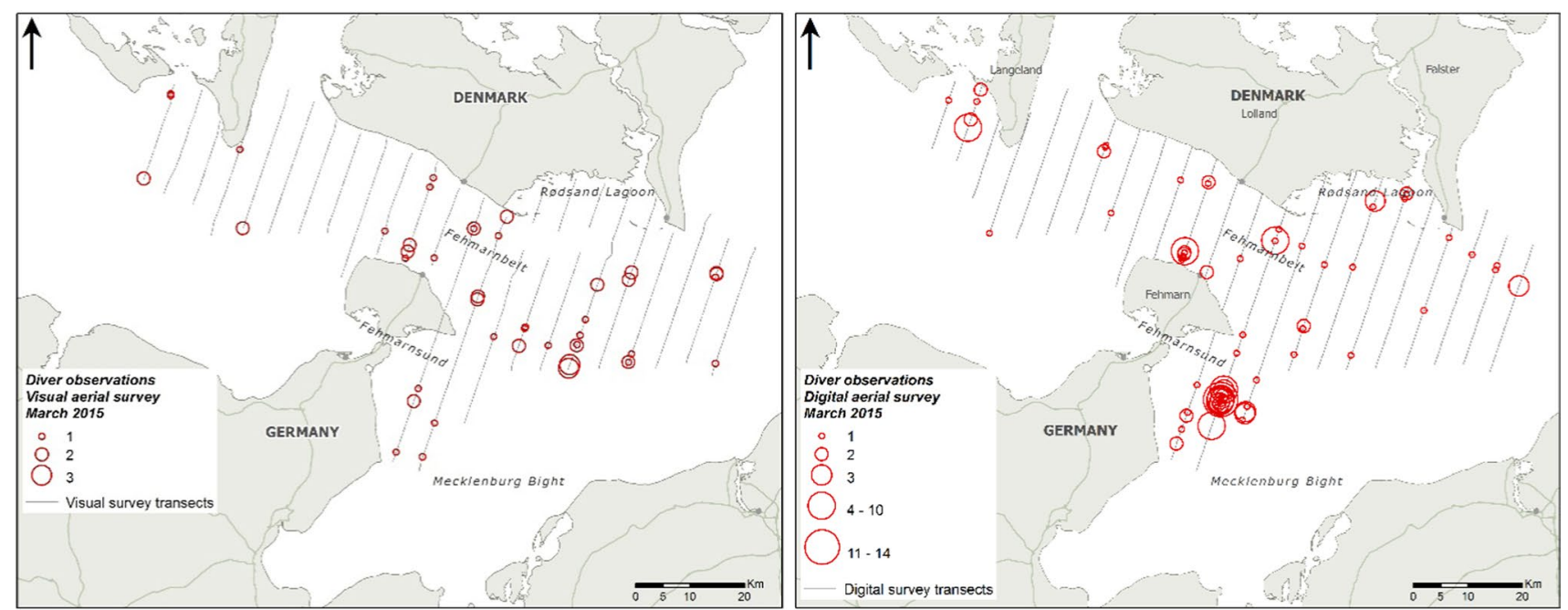

Fig. 8 Observed diver distribution during visual and digital aerial surveys conducted on 19 March 2015

The visual survey registered 15 individuals, whereas the simultaneously flown digital video survey produced 194 bird sightings. After correcting for distance detection bias, the average density in the visual survey dataset was about five times lower than the analogous value calculated using the digital video survey data (Table 3 ).

\section{Herring Gull}

The Herring Gull (Larus argentatus) was the most abundant large gull species registered during the March surveys.

During the visual survey, 704 individuals were recorded, whereas 1030 birds were registered during the parallel digital video survey. After correcting Herring Gull numbers for distance detection bias in the visual survey dataset, the

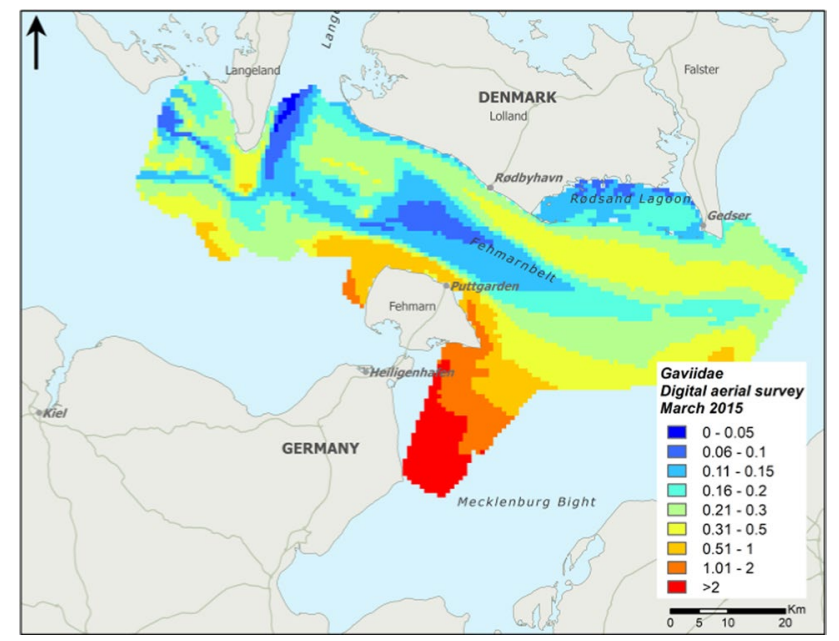

Fig. 9 Observed diver distribution during the digital aerial survey conducted on 19 March 2015 average density estimate was similar to the analogous value of the digital video survey dataset (Table 3). However, the rate of gull identification to species level was much lower during the visual survey compared to the digital survey dataset, and thus it can be assumed that much of the difference in gull sightings could be attributed to differences in identification.

\section{Discussion}

We compared the results of aerial visual and digital video surveys conducted on the same day over the southern Baltic Sea. The study area supports a diverse community of marine birds with several species occurring in very high numbers. Because the true number of birds in the area is unknown, we can only compare the results of the two survey methods with each other and assess their comparability and effectiveness for marine bird monitoring.

\section{Bird sightings}

Considering raw survey data, the digital video method registered more birds. This is apparently a simple outcome of the fact that the used HiDef video system allows an even coverage of a 544-m swath with a constant high resolution of $2 \mathrm{~cm} /$ pixel. While survey effort within the filmed area is thus constant and sufficient to allow an assumed nearly complete detection of birds within this strip, detection rates from visual surveys decrease rapidly with increasing distance from the plane, especially for smaller species. ESWs show that the effectively covered area is smaller in the visual survey (Online Resource 1). The difference in the number of sightings was especially striking for small and inconspicuous 
species: grebes, mergansers, and auks were more than ten times as numerous in the digital survey dataset. Therefore, screening of the raw survey data suggests that the digital technique provides a clear advantage by documenting species that would be missed during traditional visual aerial surveys. This has already been acknowledged in the past and it has therefore been recommended that monitoring of these species should be conducted using ship-based surveys (Diederichs et al. 2002; Camphuysen et al. 2004; BSH 2007). The difference between the digital video and observer survey methods might be enhanced in our dataset, which was collected in an area with a very high abundance of sea ducks, so that inconspicuous species might have been even more easily overlooked as the attention of the observers may have been distracted by numerous and conspicuous species. In digital video surveys, this problem is much reduced as reviewers can control the speed at which the footage is processed.

Following the survey and data handling protocols, bird observations were geographically positioned at higher spatial resolution in the digital survey dataset, the average transect segment lengths being $62 \mathrm{~m}$ in these as compared to $158 \mathrm{~m}$ in the visual survey data. Transect segments represent the smallest possible spatial resolution in the respective datasets. Thus, it is not surprising that the digital survey produced a higher number of transect segments with positive records of species observations considering their smaller sampling unit (shorter transect segment), wider effective survey strip and thus generally higher number of registered bird sightings.

\section{Species identification rates}

The digital video surveys using the HiDef system achieved high identification rates that equalled or exceeded those of the visual aerial surveys for the majority of bird taxonomic groups, with the exception of grebes. Identification rate to species level of auks in the digital dataset was also relatively low, at about $42 \%$. Apparently, a $2-\mathrm{cm}$ ground resolution, the possibility of seeing the same bird in several video frames, and the use of object measuring tools in the video analysis software proved sufficient for identification of the majority of bird species (Weiss et al. 2016). High overall species identification rates for both survey methods could be partly attributed to the dominance of sea ducks in our study area, which represent easily identifiable species. Surveying areas dominated by auks or other species that are more difficult to tell apart might result in lower overall identification rates.

High species identification rates achieved by the digital video survey in our study surpass identification rates for digital data reported by the majority of other studies. Johnston et al. (2015) reported a 23\% identification rate in digital still imagery used for surveying a seabird community dominated by auks and pelagic species such as gulls, Black-legged
Kittiwakes (Rissa tridactyla), Northern Fulmars (Fulmarus glacialis), and Northern Gannets (Morus bassanus) in offshore areas of the North Sea. Similarly, Connelly et al. (2015) reported relatively low species identification rates for HiDef video surveys conducted off the mid-Atlantic coast of the US, i.e. 53\% of Anatidae (geese, swans, and ducks), $15 \%$ of divers, $35 \%$ of gulls, and only $6 \%$ of auks and terns were identified. These authors suggested that identification rates varied by survey and season, with the highest rate of birds identified to species in March surveys; thus, overall identification rate was dependent on bird species composition in the study area and visibility conditions (Connelly et al. 2015). An older generation of the HiDef video survey system compared to the system in our study was used by Connelly et al. (2015). Weiss et al. (2016) present the only published study reporting species identification rates similar to ours; this former study was conducted using the same HiDef video system in the Kiel Bight, Baltic Sea and German Bight, North Sea.

\section{Densities and abundance estimates}

Survey effort in both visual and digital survey flights was similar, as the planes followed the same transects. The area effectively covered, however, was not identical. Under valid conditions the digital survey transect strip width is $544 \mathrm{~m}$. Although observers aimed to detect birds up to $1500 \mathrm{~m}$ away from the transect line during visual surveys, the effective half-strip width was narrow and varied from 114 to $198 \mathrm{~m}$, depending on the species observed (Online Resource 1). Also, observation was often hindered for one of the observers by the intense glare during the visual aerial surveys resulting in a reduced total area covered. When conducting digital video surveys, the camera system can be rotated away from the sun resulting in almost no loss of valid effort due to glare. Thus, for the same flight effort, the effective coverage of the survey area by visual surveys is species specific and usually smaller than the area covered by the digital surveys (544-m strip width of the digital surveys compared with $2 \times$ ESW of the visual surveys). Lower numbers of bird sightings during the visual surveys can be partly explained by a smaller area covered for species with narrow ESWs (Online Resource 1).

When bird observations were recalculated to densities, after correcting observed numbers for distance detection bias in the visual survey dataset, the general pattern remained the same, i.e. the average densities were higher for most species in the digital survey dataset. Only in the case of the Common Scoter did the correction for distance detection bias yield a higher average density in the visual survey dataset. A correction for distance detection bias accounts for some of the missed birds, but this procedure cannot be applied to 
segments where there are no bird registrations, thus a total lack of observations remains zero.

\section{Capacity for distribution modelling}

We do not focus on or discuss distribution modelling per se in this paper; instead, we compare two survey methods and believe that the general conclusions from this paper would be similar even if other modelling methods and algorithms were applied. For a thorough discussion regarding the distribution modelling approach used in this study, see Heinänen et al. (2017).

Fewer bird sightings in the visual survey dataset affected the observed and subsequently modelled distribution patterns. For rarer species that typically occur singly or in small groups, the probability of false negatives is higher for visual surveys, particularly for individuals located in the outer transect bands. Birds overlooked during the visual surveys present gaps in the distribution patterns in places where the digital surveys register observations. Also, fewer sightings during visual surveys often limit distribution modelling due to an insufficient sample size. Thus, if the aim of a study is to produce a reliable density distribution for non-abundant species, higher visual survey effort (several surveys) might be needed to collect sufficient samples compared to a digital video survey effort.

Distribution modelling improves the abundance estimates in areas with heterogeneous distribution patterns (Heinänen et al. 2017). Due to higher sighting rates and higher spatial accuracy, more accurate distribution patterns can be modelled using digital data. Statistical model performance was, in most cases, better for distribution models fitted using the digital survey dataset compared to the visual survey data (Online Resource 1).

\section{Limitations of visual and digital aerial survey methods}

Both visual aerial and digital video surveys are affected by certain biases in a similar way. The presence of diving birds on the water surface varies substantially depending on species, habitats, and period of the year; a lot of species spend a substantial proportion of the daytime foraging underwater and are thus invisible to observers and do not appear in digital images due to a short exposure period (e.g. Thaxter et al. 2013; Žydelis and Richman 2015). Although it is common to account for availability bias when analysing marine mammal sightings in aerial survey datasets (e.g. Teilmann et al. 2013), this is not usually done for birds (but see Winiarski et al. 2014). Correcting for availability bias might be more important for digital video surveys than for observer surveys because flying at a height of $549 \mathrm{~m}$ did not cause any notable behavioural response of the birds in the survey areas, as can be seen from the very high proportion of swimming birds recorded, whereas low-flying observer surveys often cause birds to flush, which is especially common in large groups of sea ducks. During digital video surveys flown at $549 \mathrm{~m}$ diving birds are assumed not to interrupt their natural behaviour, and survey results are potentially influenced by their reduced presence on the sea surface.

Furthermore, all visual survey methods have an array of inherent assumptions. For example, that all birds on the transect line are detected; that distance estimation is correct; that group size estimation is correct. Some of these assumptions are likely violated (e.g. Camphuysen et al. 2004). It is worth noting that although the way in which the video footage was processed does not allow us to correct the data for detection bias, digital video material would allow for this in the future.

\section{Future outlook}

Digital aerial surveys are newly developed methods with advantages and limitations that are not fully documented and understood due to their rather short track record. Several studies report some contradictory results. As was the case in our study, other studies often found that digital surveys yielded higher numbers of bird sightings and produced higher abundance estimates (Buckland et al. 2012; Skov et al. 2016). But there are also contradictory results suggesting lower bird sighting rates and abundance estimates produced by digital surveys compared to traditional visual ship-based surveys (Connelly et al. 2015; Williams et al. 2015).

The digital survey technique would benefit from further technological development to increase image resolution to produce higher identification rates of the species that are still problematic. Also, moving towards machine learning and automated object identification and species recognition using digital video or photo material would greatly decrease the data processing time for digital surveys and reduce associated costs.

There is a need for future studies to assess the comparability between aerial digital surveys and visual ship-based surveys. Further, it is essential to evaluate how the results of digital surveys compare with absolute (known) numbers of birds. Accounting for bird visibility (e.g. birds being submerged during aircraft flyover) could partly help us approach "true" abundance estimates. Our investigation, as well as similar work by other authors (e.g. Connelly et al. 2015; Johnston et al. 2015; Williams et al. 2015), revealed that bird identification, and possibly detection, is species specific during digital surveys. Therefore, comparative studies conducted in areas with different marine bird species compositions would further improve our understanding of digital survey methods. Finally, as for observers in visual aerial surveys, the accuracy of digital survey results 
are highly reliant on the skill and diligence of specialists who work with the survey material, detect and identify birds, and perform QA. To our knowledge, no formal, peer-reviewed guides exist for species identification from digital survey material, and this may lead to an unequal ability of different teams to examine material. Knowledge and experience sharing are fundamental when we seek to achieve the best use of collected material and comparison between different datasets.

\section{Conclusion}

This study presents a comprehensive comparison of digital and visual aerial surveys including a range of marine bird species based on the same transects surveyed close in time. The main findings are:

1. More bird sightings were recorded for each taxonomic group during the digital video survey. The number of sightings of small and inconspicuous species, such as grebes and auks, was particularly increased by the digital survey method and exceeded the number of detections achieved during the visual survey by a factor of $>10$.

2. More species were registered during the digital survey than during the visual survey. Overall, identification rates to species level were similar for both survey methods at over $90 \%$; however, there were marked differences among taxonomic groups.

3. Higher densities of nearly all bird species/taxonomic groups were estimated by the digital survey method except for Common Scoter, compared to densities calculated from the visual survey dataset after correcting the data for species-specific distance-detection bias.

4. With similar survey effort, the digital survey dataset allows the application of distribution modelling for more species than the visual survey data, due to larger sample size. To achieve comparable results, more visual surveys would have to be conducted over the same study area.

5. Higher bird detection rates reduce type II errors in the digital survey dataset and thus presumably enable the calculation of more realistic species distribution patterns at higher resolution.

Overall, we found the digital video survey technique to be more advantageous than the visual aerial survey for all aspects of the study when comparing the results of simultaneous survey flights. This conclusion, however, does not decrease the value of visual aerial surveys as monitoring methods for marine birds, which remain important for long-term monitoring. Indeed, the chosen survey method should match the objectives of the study in question.

Acknowledgements The study was funded by Femern A/S. We thank the pilots from BioFlight who flew the survey planes, the observers who counted birds during the visual survey, and the object detection and identification teams who processed the digital video footage. Bjarne Holm Jakobsen, Femern A/S, and Andy Webb, HiDef Aerial Surveying, provided helpful comments on the manuscript. We also thank two anonymous reviewers, whose constructive comments helped to improve the manuscript.

Open Access This article is distributed under the terms of the Creative Commons Attribution 4.0 International License (http://creativeco mmons.org/licenses/by/4.0/), which permits unrestricted use, distribution, and reproduction in any medium, provided you give appropriate credit to the original author(s) and the source, provide a link to the Creative Commons license, and indicate if changes were made.

\section{References}

BSH (2007) Standard-investigation of the impacts of offshore wind turbines on the marine environment (StUK3). Bundesamt für Seeschifffahrt und Hydrographie, Hamburg and Rostock

BSH (2013) Standard-investigation of the impacts of offshore wind turbines on the marine environment (StUK4). Bundesamt für Seeschifffahrt und Hydrographie, Hamburg and Rostock

Buckland ST, Anderson DR, Burnham KP, Laake JL, Borchers DL, Thomas L (2001) Introduction to distance sampling: estimating abundance of biological populations. Oxford University Press, London

Buckland ST, Burt ML, Rexstad EA, Mellor M, Williams AE, Woodward R (2012) Aerial surveys of seabirds: the advent of digital methods. J Appl Ecol 49:960-967

Burt L, Rexstad E, Buckland S (2009) Comparison of visual and digital aerial survey results of avian abundance for Round 3, Norfolk Region. COWRIE Rep

Camphuysen KCJ, Fox AD, Leopold MF, Petersen IK (2004) Towards standardised seabirds at sea census techniques in connection with environmental impact assessments for offshore wind farms in the UK. COWRIE-BAM-02-2002 Rep

Connelly EE, Duron M, Williams KA, Stenhouse IJ (2015) Summary of high resolution digital video aerial survey data. In: Williams KA, Connelly EE, Johnson SM, Stenhouse IJ (eds) Wildlife densities and habitat use across temporal and spatial scales on the MidAtlantic outer continental shelf: final report to the Department of Energy EERE Wind and Water Power Technologies Office. Report BRI 2015-11. Biodiversity Research Institute, Portland, p 34

Diederichs A, Nehls G, Petersen IK (2002) Flugzeugzählungen zur großflächigen Erfassung von Seevögeln und marinen Säugern als Grundlage für Umweltverträglichkeitsstudien im Offshorebereich. Seevögel 23:38-46

Heinänen S, Žydelis R, Dorsch M, Nehls G, Skov H (2017) Highresolution seabird distribution modelling: relating aerial and ship surveys data to food resources, anthropogenic pressures, and topographic variables. Condor 119:175-190

Johnston A, Thaxter CB, Austin GE, Cook ASCP, Humphreys EM, Still DA, Mackay A, Irvine R, Webb A, Burton NHK (2015) Modelling the abundance and distribution of marine birds accounting for uncertain species identification. J Appl Ecol 52:150-160 
Marsh H, Sinclair DF (1989) Correcting for visibility bias in strip transect aerial surveys of aquatic fauna. J Wildl Manage 53:1017-1024

Miller DL (2015) Distance: distance sampling detection function and abundance estimation. $\mathrm{R}$ package version 0.9.4. http://CRAN.Rproject.org/package=Distance. Accessed 01 Dec 2018

Pearce J, Ferrier S (2000) Evaluating the predictive performance of habitat models developed using logistic regression. Ecol Modell 133:225-245

Reid JB, Camphuysen CJ (1998) The European seabirds at sea database. Biol Cons Fauna 102:291

Skov H, Heinänen S, Thaxter CB, Williams AE, Lohier A, Banks AN (2016) Real-time species distribution models for conservation and management of natural resources in marine environments. Mar Ecol Prog Ser 542:221-234

R Core Team (2014) R: a language and environment for statistical computing. R Foundation for Statistical Computing, Vienna, Austria. http://www.R-project.org/. Accessed 01 Dec 2018

Teilmann J, Christiansen CT, Kjellerup S, Dietz R, Nachman G (2013) Geographic, seasonal, and diurnal surface behaviour of harbour porpoises. Mar Mammal Sci 29:E60-E76

Thaxter CB, Burton NHK (2009) High definition imagery for surveying seabirds and marine mammals: a review of recent trials and development of protocols. British Trust for Ornithology report, commissioned by Cowrie Limited

Thaxter CB, Daunt F, Gremillet D, Harris MP, Benvenuti S et al (2013) Modelling the effects of prey size and distribution on prey capture rates of two sympatric marine predators. PLoS One 8(11):e79915. https://doi.org/10.1371/journal.pone.0079915

Webb A, Irwin C, Mackenzie M, Scott-Hayward L, Caneco B, Donovan C (2017) Lincs wind farm: third annual post-construction aerial ornithological monitoring report. Unpublished report, HiDef Aerial Surveying Limited for Centrica Renewable Energy Limited. CREL LN-E-EV-013-0006-400013-007

Weiss F, Büttger H, Baer J, Welcker J, Nehls G (2016) Erfassung von Seevögeln und Meeressäugetieren mit dem HiDef Kamerasystem aus der Luft. Seevögel 37:14-21

Williams KA, Connelly EE, Johnson SM, Stenhouse IJ (eds) (2015) Wildlife densities and habitat use across temporal and spatial scales on the Mid-Atlantic outer continental shelf: final report to the Department of Energy EERE Wind and Water Power Technologies Office. Award no. DE-EE0005362. Report BRI 2015-11, Biodiversity Research Institute, Portland, Maine, p 715

Winiarski KJ, Burt ML, Rexstad E, Miller DL, Trocki CL, Paton PWC, McWilliams SR (2014) Integrating aerial and ship surveys of marine birds into a combined density surface model: a case study of wintering Common Loons. Condor 116:149-161

Wood SN (2011) Fast stable restricted maximum likelihood and marginal likelihood estimation of semiparametric generalized linear models. JR Stat Soc (B) 73(1):3-36

Žydelis R, Richman SE (2015) Foraging behavior, ecology, and energetics of sea ducks. In: Savard J-PL, Derksen DV, Esler D, Eadie JM, Skean VW (eds) Ecology and conservation of North American sea ducks. Studies in Avian Biology, vol 46. CRC, Boca Raton, p 243

Publisher's Note Springer Nature remains neutral with regard to jurisdictional claims in published maps and institutional affiliations.

\title{
Affiliations
}

\author{
Ramūnas Žydelis ${ }^{1,3} \cdot$ Monika Dorsch $^{2} \cdot$ Stefan Heinänen ${ }^{1} \cdot$ Georg Nehls ${ }^{2} \cdot$ Felix Weiss $^{2}$ \\ Ramūnas Žydelis \\ zydelis@ornitela.eu \\ 3 Present Address: Ornitela UAB, Švitrigailos gatvè 11K-109, \\ LT-03228 Vilnius, Lithuania
}

1 DHI, Agern Allé 5, 2970 Hørsholm, Denmark

2 BioConsult SH, Schobüller Strasse 36, 25813 Husum, Germany 